\title{
Stirling Engine and oil-free compressors
}

\author{
Thierry Raballand ${ }^{1}$ \\ ${ }^{1} 22$ rue de Ouagadougou, 33300 Bordeaux, France
}

\begin{abstract}
Refering to figure 1 [Fig.1], an oscillating «flipper» piston (1) and its associated chamber (2) are maintained without reciprocal contact. No oil is required because there is no contact and so no friction. An oscillating shaft (22) maintains the oscillating « flipper »piston (1). Around shaft (22), a twisting seal (8) allows for absolute sealing. This characteristic is important for Stirling engines and oil-free compressors. Referring to figure 4 [Fig.4], the two oscillating « flipper » pistons on the left belong to a Stirling-Franchot engine, more particularly to a Stirling-Franchot engine with two oscillating "flipper» pistons and so with two quadric crank mechanisms. The oscillating « flipper » piston on the right belongs to an oil-free compressor. The Stirling engine shaft (11), which is in alternative rotation, directly powers the oil-free compressor shaft (22). This prevents the use of a third quadric crank mechanism from shaft (33) to shaft (22). A Stirling engine connected to an oilfree compressor is useful when the fluid is precious or dangerous. A French patent was taken out on Februar 1st, 2020.
\end{abstract}




\section{PROBLEM}

\subsection{Need for oil-free compressors}

"Reliable oil-free compressors are generally not available at present" wrote Walker and Bingham in 1994 [1].

\subsection{Friction-free compressors}

In order to avoid oil, friction must be avoided too and so the piston must be guided.

\section{SOLUTION}

\subsection{A new piston design: the "flipper" piston}

The "flipper" piston is an oscillating piston mentioned in the patent [2] in 2002.

It refers to a prismatic oscillating piston. As it is guided, there is no friction and so no oil is necessary. Two "flipper" pistons are required for the Stirling-Franchot engine and one "flipper" piston is required for the compressor.

\subsection{Design of the compressor}

Considering the compressor, look at figures Fig.1 and Fig.2. The "flipper" piston (1) is guided by the shaft (22). This "flipper" piston (1) and the chamber (2) enables volume changes. Fluid transfer is possible in the compressor.

Considering the engine and the compressor, look also at figures Fig.3 and Fig.4. In figure Fig.3, an indirect power transmission (11-33-22) between the engine and the compressor was the initial power transmission means. But in figure Fig.4, a direct power transmission (11-22) between the engine and the compressor is the final power transmission means.

Considering figure Fig.5, the compressor has four valves: two valves $(41,43)$ for the inlet and two valves $(42,44)$ for the outlet.

Seal (8) must be improved.

\section{References}

[1] G. Walker, E.R. Bingham, Low Capacity Cryogenic Refrigeration, page 2, 1994

[2] T. Raballand, French patent FR2846374, 2002 

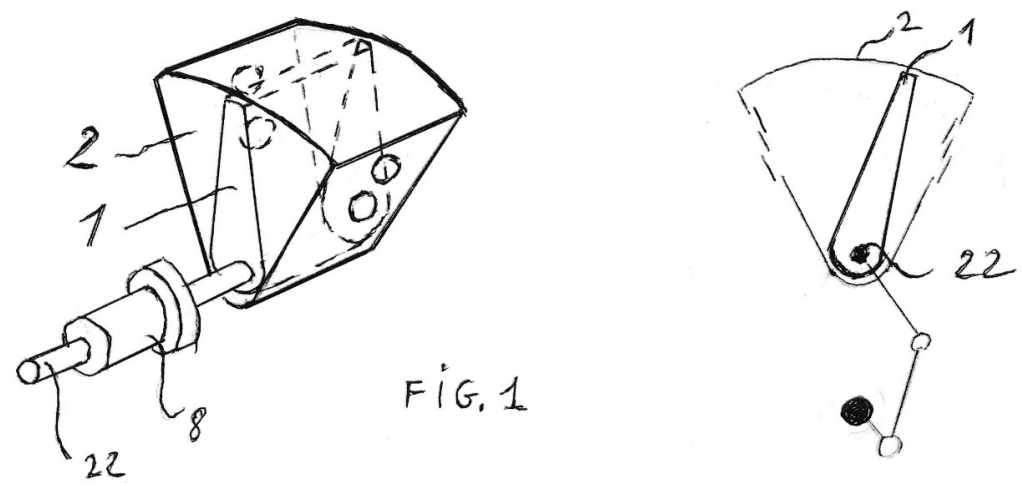

Fig. 2

Fig. 1. Oscillating piston (1), associated chamber (2),seal (8) and oscillating shaft (22)

Fig. 2. Oscillating piston (1), associated chamber (2) and oscillating shaft (22)
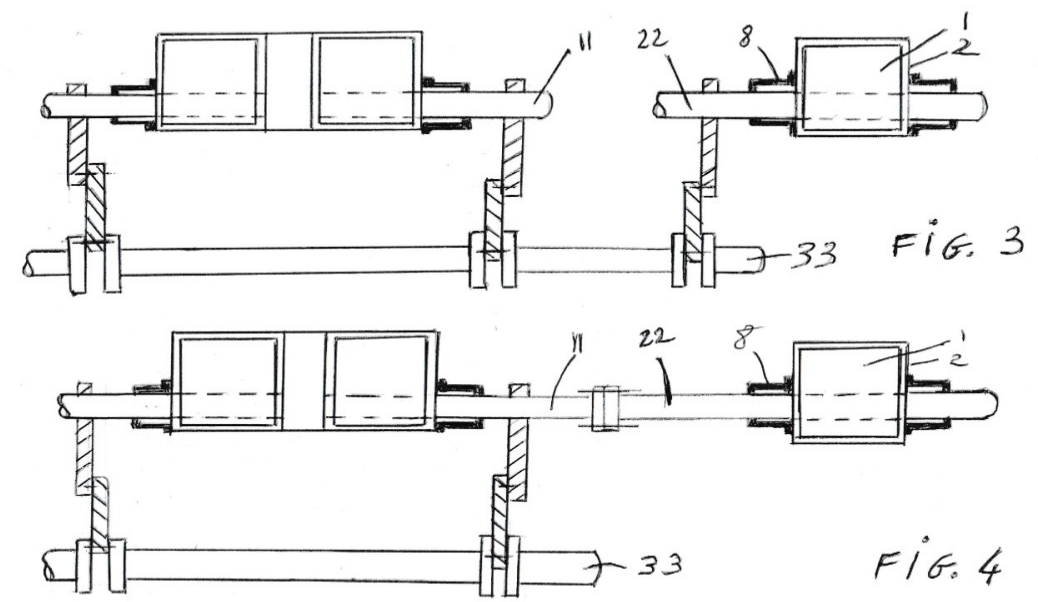

Fig. 3. The Stirling-Franchot engine shaft (11) which is in alternative rotation, indirectly powers the oil-free compressor oscillating shaft (22) via the shaft (33) which is in continuous rotation thanks to a quadric crank mechanism.

Fig. 4. The Stirling-Franchot engine shaft (11) which is in alternative rotation, directly powers the oilfree compressor oscillating shaft (22) 


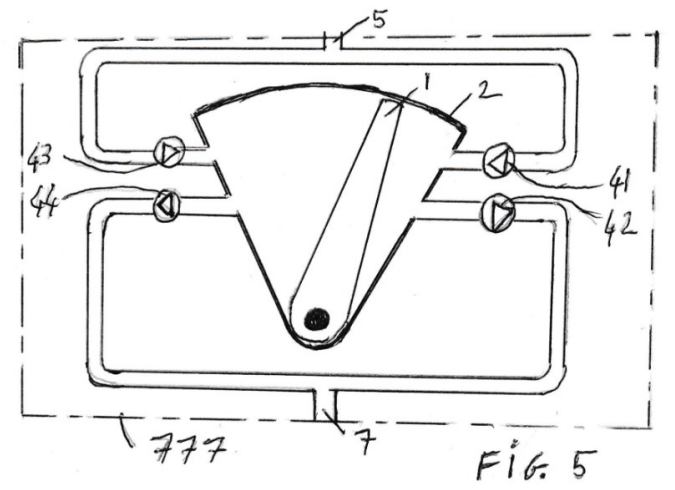

Fig. 5. The oscillating piston (1) and its associated chamber (2) let the fluid in through the valves (43) and (41) and then force it out through the valves (42) and (44). 